\title{
Construction of the Integral Teaching Content on the Innovative Electrical Class Technical Personnel
}

\author{
Shuguang Liu, Bo Dong, and Yan Sun \\ School of Electronic and Information Eng. Xi'an Polytechnic University, Xi'an 710048, China \\ email: L_shuguang@yahoo.com
}

Keywords: Electrical Class Technical Personnel; Innovative Education; Integral Teaching Content

\begin{abstract}
By analyzing and designing the connotation of talent training, electrical class professional teaching content system and its implementation strategy, we confirmed the innovative electrical class technical personnel's training contents, training methods and training mode, especially proposed an idea of combining the professional practice activity of in-classes with that of out-classes, that can promote students' innovation ability and process practice ability and has certain significance for strengthening and deepening electrical class specialized education reform, optimizing cultivation and content, improving the quality of talent training.
\end{abstract}

\section{The Meaning and Objectives of the Integration of Personnel Training}

To cultivate the creative talents and innovative spirit and creative ability, we must first accurately understand and grasp the quality of its constituent elements of the innovative talents, on this basis, we must constantly update their concepts, to reform the curriculum, teaching models and practices and other aspects, explore and build personnel training model and implementation mechanisms conducive to the talent to stand out.

\section{A. The constituent elements of innovation capability}

The innovation is based on the specific material conditions, social environment and mechanism system which has distinctive personalized and collaborative thinking and practice. The innovation activities has five basic characteristics: (1) Dependent. Regardless of the level of innovation and innovative activities that to achieve the level of certain material conditions, human environment and the machine anchor system can be carried out; (2) Personalized. The innovative activities and innovation in the main outlook on life, values, thinking and behavior is closely related to innovation activities with personalized innovative results so they could not; (3) Collaboration. In the era of knowledge economy, innovation activity is not a force to complete the things people alone, but the team division of labor, it is necessary to fully demonstrate the personality, strengths, and can learn from each other, seek common ground while reserving differences, and form the atmosphere of "knowledge sharing", "common innovation"; (4) Long-term. The innovative results can not be a pinch, often to go through to the application from the demonstration to the empirical, from experiments from theory to practice, multiple repeated to get; (5) Cumulative. The innovation activities is a relay activities, new and innovative activities on the basis of past innovation activities and their results and experience, innovative practice or systematic practice of innovation training, did not carry out innovation activities with the necessary knowledge, skills, methods and experience of the accumulation and reserves it is impossible to carry out new, high level of innovation activities, the same time, a new and innovative activities, regardless of success or failure for the next innovation activities accumulated. Therefore, innovative subjects must be fully aware of and understand the meaning and characteristics of innovation and innovation activities, study and work from the start bit by bit, the accumulation of exercise and develop the concept of innovation and manage innovation activities, awareness, knowledge, thinking, skills, and methods to form and have the ability to innovate.

Visible, innovation and innovative subjects to engage in innovative activities, manage innovation activities should have the concept of awareness, knowledge, thinking skills, methods can be summed 
up to include three levels of eight elements.

The first level is the quality of innovation is different from the others more or less permanent personality characteristics subjects in the study and practice activities to develop the sense of innovation and innovative fine two.

The second level is the innovative thinking is an intellectual activity to create personalized, organic combination of creative activities in a variety of types of thinking is the core of the creative, generally including logical thinking and logical thinking, divergent three aspects of thinking and convergent thinking, subconscious thinking and significant conscious thought, the most prominent is the cumulative effect and personalization.

The third level is the innovative skills, innovative main innovation operational technologies and capabilities, including the three aspects of the stock of knowledge, technical reserves and innovative skills.

Innovative capacity of the three levels of eight elements of organic combination, promoted by each other to constitute the overall innovation capability. Innovation and quality is the driving force of innovation and ability to develop and development, plays a dominant role in the formation and development of innovation activities and innovation capability; innovative thinking is the core of the innovation capacity, source of ideas for innovation; innovation skills are innovative subjects in innovation quality to lead and drive, innovative thinking results, means, methods and skills materialized. Although the status and role of the three levels of elements in the overall innovation capability is different, but complementary and indispensable Otherwise, innovation will be greatly reduced.

In summary, the train has a certain quality of innovation, creative thinking and innovation skills, innovative engineering and technical personnel, must be constructed for students and professional characteristics, teaching content system integration, develop appropriate implementation modalities and mechanisms be achieved the goal of innovative engineering and technical personnel training.

\section{B. The connotation of an integrated system of teaching content}

For major in engineering, integration mainly contains three aspects of meaning.

(1) Integration of general education and professional education

General Education also known as general education, general education and liberal education is not obvious a wide range of professional, non-utilitarian knowledge, skills and emotional attitude of education aimed at cultivate all-round development of society are willing to have the ability to actively participate in social life, social responsibility and citizen of a country. The superiority of the two aspects of general education, first, to help train people with a sense of social responsibility to help develop innovative.

The essence of general education and professional education are not mutually exclusive. General education so that students can understand and learn perspective and way of thinking in different disciplines to understand the different knowledge systems asked the inherent unity and difference, so that students learn mastery in wisdom, to develop the habits and methods of their own independent thinking. Professional education not only give students a systematic, rigorous professional knowledge and professional training. Also allows students to grasp the depth of the spirit of a particular area to learn and explore the experience and skills to help students develop the academic exploration and technological innovation as well as thinking and problem-solving skills. Thus, general education and professional education only blend rely on each other in order to complement each other in order to make the overall development of students, in order to cultivate creative talents.

(2) Integration of professional theoretical teaching and practical teaching Electronic information science and technology professionals is a theoretical and practical highly professional, mainly in the following areas. First, professional theoretical basis for professional practice, is key to advancing in the right direction to ensure that professional practice and the lighthouse; professional practice is the cognitive activity of the test engineering and scientific value of the professional theories, it is to exercise and train students to identify problems and problem-solving skills practice activities; all the problems encountered in the professional theory can not be exhaustive process of practice and practical knowledge and skills, and only carried out under the guidance of professional theory, 
practice and perfect professional theory and application of professional theory the ability of professional practice in order to foster the practice of awareness, practical ability, and even the sense of innovation and innovation capacity. Therefore, we must content and convergence, depth and difficulty, the quality and quantity of the two blends.

(3) Planned integration of practical activities to practice activities and plans

Planned practice teaching is often limited by the total number of credits, number of hours, compared with professional theory courses, credits and hours less, and there is a considerable part of the practice teaching is equivalent to the general education of professional education can not meet the personalized specialized training needs of professional competence. Its practical effect is poor. Therefore, we must open experiment, the students' independent science and technology activities and contests unplanned practice as a carrier to give full play the main role of students in professional practice, training students to use professional knowledge and technical ability to identify problems, analyze problems and problem-solving abilities, to achieve the purpose of temper and cultivate students' creative spirit and innovative thinking. To achieve this goal, we must make the plan practice integration and the integration of practice and plans.

In reality innovation capability training, general education focuses on the cultivation of the sense of innovation and the spirit of innovation and quality of innovation, professional education focused on the cultivation of innovative thinking, professional practice focuses on innovation and skills development, and only three in the content and form interacting with each other and blend could truly achieve the training purpose of students' creative ability value.

\section{System of Integrated Teaching Content}

\section{A. Electronic Information Science and Technology Curriculum}

General Education courses: including the ideological and moral cultivation, Mao Zedong Thought, Deng Xiaoping Theory, the basic principles of Marxist philosophy, legal basis, college English, college sports, higher mathematics, engineering, mathematics, university physics and its experimental computer culture, computer language and programming courses so that students understand the history of loving the motherland, to establish a scientific world outlook and outlook on life, the concept of knowledge and talent, discipline, and a grasp of basic mathematical and physical basis of knowledge and ways of thinking, and computer and foreign language foundation knowledge and lay the foundation for the follow-up study of the professional foundation courses and further education.

Professional education courses: covering the e-science, information science and computer science, the main subjects. Can be divided into four broad categories: (1) circuit categories: circuit analysis, analog electronics, digital electronics, high frequency electronic circuit, EDA technology and application programs and their experiments, so that students master a variety of electronic circuit analysis and calculation, and The basic design calculations and the use of computer simulation aided design methods; (2) signal, and analysis: Signals and Systems, Digital Signal Processing and its experimental purpose is to enable students to master electronic information science and technology in signals and systems analysis, signal and information processing theory and methods; (3) communication and information transmission categories: including information theory and coding theory, communication theory, optical fiber communications principles and technology courses and their experiments, so that students master the basic theory and technology of communications; (4) computer application technology categories: computer theory, Principles and Applications, DSP principles and application of course their experiment, the purpose is to enable students to master the hardware components of computers and a variety of microprocessor as the core of intelligent systems and The working principle, to lay the foundation for intelligent digital system design and integration.

Professional direction of platform: In order to fully respect and play to the personality of the school, to develop specialized knowledge and skills of the students, under the experimental conditions and similar circumstances, to establish the application of electronic technology, Optical Information Science and Technology and Communications Science and Technology, three 
professional direction, corresponding courses include sensing technology and application of digital system design, electronic process on the basis of integrated circuit applications, photonics technology, modern display technology, optical information processing, network communications, modern switching technology, mobile communication technology, communications, software engineering, so that students able to master the basic application of electronic information science and technical expertise in a particular area, to facilitate the employment of graduates; also set up a multi-professional courses of study to encourage students to cross the direction of electives enables students to broaden employment opportunities, and after further studies.

B. Integration of teaching and professional activities system

Content system for the integration of teaching and professional activities is shown in Fig.1.

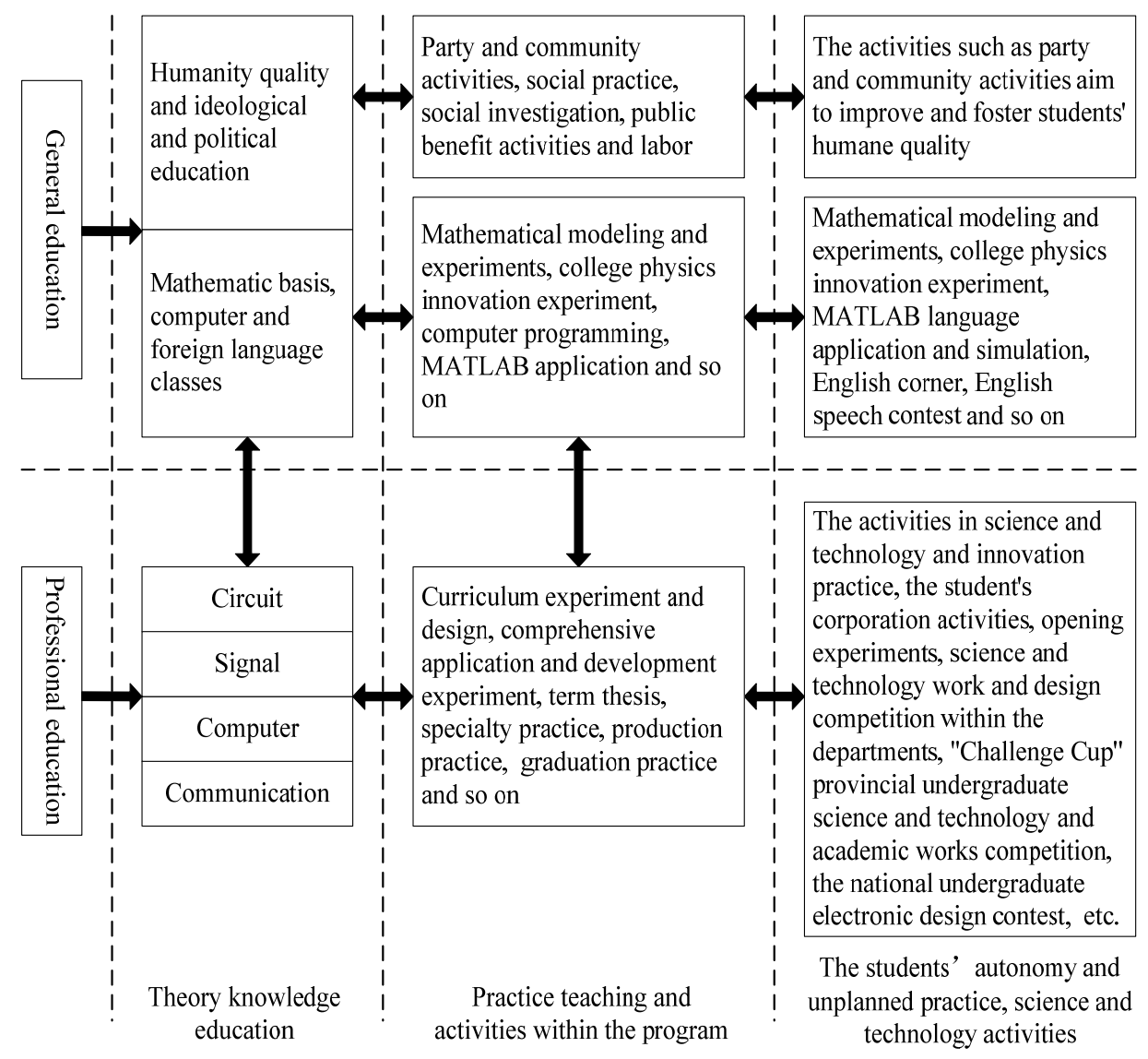

Figure 1 Content system for the integration of teaching and professional activities

\section{References}

[1] Jiang Jingling. Innovation capability elements and Graduate Education. Chinese graduate student, 2006, (2) :44-45.

[2] Shiyong Fang, Wang Haiyong. Capacity and quality of the innovative talents training mode and practice. Scientific and technological innovation Herald. 2008, (8): 217

[3] Providing Service for Agriculture. On the basic characteristics of the innovation and quality of talent. Jiangsu Institute of Education Technology (Social Science Edition), 2000,16 (2) :1-7.

[4] Fang Guozhong, Wang Xiaojun. Innovative talent quality model based on personality traits. Northeast Normal University (Social Science Edition), 2007, 227 (3) : 106-109.

[5] Duan Xiaohong, Zhang Guomin. A Brief Discussion on the creative talents and quality characteristics. Shanxi Agricultural University (Social Science Edition), 2004, 3 (3) :223-225.

[6] Li Jiang. General education: to cultivate a sense of social responsibility and innovative people. http://www.ynufe.edu.cn/news2/NewsShowArticl.asp? ArticleID=8191. 